\title{
Long-term follow-up of patients with small bowel angiodysplasia on capsule endoscopy. Determinants of a higher clinical impact and rebleeding rate
}

\author{
E. Redondo-Cerezo, C. J. Gómez-Ruiz, N. Sánchez-Manjavacas, M. Viñuelas, C. Jimeno, \\ G. Pérez-Vigara, J. Morillas, J. I. Pérez-García, J. García-Cano and A. Pérez-Sola \\ Gastroenterology Department. Virgen de la Luz General Hospital. Cuenca, Spain
}

\section{RESUMEN}

Introducción: no se ha definido con exactitud el impacto clínico de las angiodisplasias del intestino delgado. Presentamos un estudio prospectivo para determinar las características de los individuos con mayor riesgo de recidiva hemorrágica o peor evolución clínica.

Pacientes y métodos: en este estudio se incluyeron treinta pacientes con angiodisplasias, halladas con la cápsula endoscópi$\mathrm{ca}$, que fueron seguidos durante 12 meses. Las lesiones se clasificaron por su tamaño en pequeñas $(\leq 10 \mathrm{~mm}$ ) o grandes (> 10 $\mathrm{mm}$ ). Estudiamos también el número de angiodisplasias en cada paciente. La recidiva hemorrágica se definió como una caída en las cifras de hemoglobina de $2 \mathrm{~g} / \mathrm{dl}$, en ausencia de melenas o hematoquecia para la hemorragia de origen oscuro o en presencia de cualquiera de estas manifestaciones.

Resultados: se realizaron procedimientos terapéuticos en 13 pacientes $(43,4 \%)$. Los pacientes con angiodisplasias grandes tuvieron mayores requerimientos transfusionales, un mayor número de procedimientos diagnósticos realizados tras la cápsula endoscópica, cifras inferiores de hemoglobina y menor tasa de recidiva hemorrágica. Los pacientes con diez o más angiodisplasias recibieron también más transfusiones y presentaron cifras inferiores de hemoglobina, pero no hubo diferencias en los procedimientos terapéuticos o recidiva hemorrágica entre ambos grupos. En el seguimiento, la recidiva hemorrágica se detectó en 5 pacientes $(16,7 \%)$, todos con angiodisplasias pequeñas. Esta fue más frecuente en pacientes que no recibieron tratamiento (23,53 vs. $7,69 \% ; p=0,037)$

Conclusiones: el tamaño $\geq 10 \mathrm{~mm}$ de las angiodisplasias determina un mayor impacto clínico y más posibilidades de recibir tratamiento. Nuestros hallazgos indican que pacientes con lesiones de mayor tamaño se beneficiarían de procedimientos terapéuticos con una reducción de la tasa de recidiva hemorrágica.

Palabras clave: Capsulo endoscópica. Hemorragia digestiva de origen oscuro. Angiodisplasia.

\begin{abstract}
Background: the clinical impact of small-bowel angiodysplasia has not been defined. We present a prospective study to determine the features of individuals with a higher risk of rebleeding or a worse clinical outcome.

Patients and methods: thirty patients with angiodysplasia found on CE were included and followed for 12 months. Angiodysplasia were classified by their size as small $(\leq 10 \mathrm{~mm})$ or large $(>10 \mathrm{~mm}$ ). We also studied angiodysplasia lesion numbers in each patient. Rebleeding was defined as a hemoglobin drop of more than $2 \mathrm{~g} / \mathrm{dl}$ in the absence of melena or hematochezia in the case of occult GI bleeding, or with any or both manifestations.

Results: a therapeutic procedure was carried out in 13 patients (43.4\%). Individuals with large angiodysplasia had higher transfusion requirements, a higher proportion of therapeutic procedure performed after $\mathrm{CE}$, lower hemoglobin concentration, and a lower rebleeding rate. Patients with ten or more angiodysplasia lesions had also higher transfusion requirements and lower hemoglobin levels, but we found no differences in the number of therapeutic procedures or rebleeding rate between both groups. On follow up rebleeding was detected in 5 patients (16.7\%), all of them with small angiodysplasias. Rebleeding was more frequent in patients who did not receive further interventions (23.53 vs. 7.69\%; $p=0.037$ ).

Conclusions: angiodysplasia size $\geq 10 \mathrm{~mm}$ determines a worse clinical impact and more possibilities of receiving a therapeutic procedure. Our findings support that patients with large lesions would benefit from therapeutic interventions with a reduction in rebleeding rate.
\end{abstract}

Key words: Capsule endoscopy. Obscure gastrointestinal bleeding. Angiodysplasia.

Redondo-Cerezo E, Gómez-Ruiz CJ, Sánchez-Manjavacas N, Viñuelas M, Jimeno C, Pérez-Vigara G, Morillas J, Pérez-García JI, García-Cano J, Pérez-Sola A. Long-term follow-up of patients with small bowel angiodysplasia on capsule endoscopy. Determinants of a higher clinical impact and rebleeding rate. Rev Esp Enferm Dig 2008; 100: 202-207. 


\section{INTRODUCTION}

Wireless capsule endoscopy (WCE) has shown a good diagnostic yield for obscure gastrointestinal bleeding, better than push enteroscopy (1), barium follow through (2) and computed tomography (3). Nevertheless, concerns arise about the impact on clinical outcome, and more studies are needed to further determine the clinical significance of findings (4). Between $20-40 \%$ of patients with documented bleeding had no abnormalities detected by WCE and the clinical relevance of some findings has not yet been defined (5-8). Angiodysplasia is among the most usual WCE findings in most studies $(5,9-11)$, but the clinical impact of this diagnosis has not been accurately defined, although a high rate of rebleeding has been reported in a follow-up study (9). Although a significant number of patients with no bleeding episodes have small bowel lesions, no studies have correlated the size and number of intestinal angiodysplasia with the outcome of a given patient.

We therefore conducted a prospective observational follow up study in which patients with angiodysplasia found by WCE were recruited to a one year follow-up. The aim was to determine the characteristics of individuals with a higher risk of rebleeding, or a worse clinical outcome.

\section{PATIENTS AND METHODS}

Thirty prospectively recruited patients referred to the Hospital Virgen de la Luz of Cuenca, between October 2003 and August 2005, with a WCE diagnosis of angiodysplasia were included. Indications were obscure occult gastrointestinal (GI) bleeding in $16(53.3 \%)$, obscure overt GI bleeding in $14(47.7 \%)$.

Patients were given standard instructions for the procedure and informed consent was obtained. The day before, patients started a fasting period, beginning at midnight. Given video capsule endoscopy (Given Imagin ${ }^{\mathrm{TM}}$ Ldt., Yoqneam, Israel) was swallowed in the morning and patients stayed in hospital, under sanitary supervision during the recording. They were allowed to drink fluids after 3 hours, and to consume a light meal after 5 hours. The recorder was retired about nine hours after the beginning. We prolonged this period because we wanted to verify capsule battery exhaustion in every case. Patients were advised to avoid exposure to magnetic fields until capsule excretion.

Three gastroenterologists with endoscopic experience viewed all the capsule videos. Interobserver agreement was higher than $95 \%$. Any controversial finding was extensively discussed. The size of angiodysplasia was an estimate based on the experience of the main investigator (ERC), with more than $250 \mathrm{CE}$ studies interpreted, who reviewed the findings of every CE study. We also collected the number and location of angiodysplasia in each patient.
Angiodysplasia were classified by their relative size in small $(\leq 10 \mathrm{~mm}$ diameter) or large $(>10 \mathrm{~mm})$ size.

All findings on $\mathrm{CE}$ were revealed to the referring physicians, and the patients' subsequent management was directed by them. As we are a referral center, information about the follow-up was collected from our records in the group of patients from our area, and from clinical records reported to us from the referring gastroenterologists in the rest. We also interviewed patients telephonically six month and one year after the procedure's performance.

Information about blood tests, recurrent gastrointestinal bleeding, additional diagnostic or therapeutic procedures, red cells transfusions before $\mathrm{CE}$, and subjective health perception were collected. Rebleeding was defined as an unexplained hemoglobin drop of more than $2 \mathrm{~g} / \mathrm{dl}$, in the absence of melena or hematochezia in the case of occult gastrointestinal bleeding, o with any or both manifestations in the case of overt bleeding.

Patients with other bowel lesions were excluded, as they might bias our results.

\section{Statistical analysis}

The SPSS software (version 11.0; SPSS Inc, Chicago, Illinois, USA) was used for statistical analysis. The paired t-Student test, Chi square test or Fisher exact test were used to determine any significant difference in the clinical parameters. A p-value of less than 0.05 was considered as statistically significant.

\section{RESULTS}

Thirty patients with a diagnosis of intestinal angiodysplasia were recruited. The median age of these patients was 66 years (range 36 to 85 years). The mean number of upper and lower endoscopies performed before $\mathrm{CE}$ was 1.9 and 1.7 per patient respectively. Details of size and number of angiodysplasia of these 30 patients are listed in tables I and II.

Interobserver agreement between the three CE-gastroenterologists was higher than $95 \%$. Any controversial finding was extensively discussed.

A therapeutic procedure was carried out in 13 patients (43.4\%), two patients died, and the rest underwent a clinical follow-up for several reasons: Spontaneous remission of gastrointestinal bleeding, patient's denial to undergo further explorations, or clinical concerns about patients tolerance to invasive procedures in otherwise elderly or deteriorated patients. Two patients had been receiving anticoagulation before $\mathrm{CE}$, both because prosthetic cardiac valves, one with small angiodysplasia and one other with a large angiodysplasia. No other comorbidities were reported. 
Table I. Management of patients attending to angiodysplasia size

\begin{tabular}{lccccc}
\hline Size & $\begin{array}{c}\text { Number } \\
\text { of cases }\end{array}$ & Laparotomy & $\begin{array}{c}\text { Push } \\
\text { enteroscopy }\end{array}$ & $\begin{array}{c}\text { Double balloon } \\
\text { enteroscopy }\end{array}$ & $\begin{array}{c}\text { Clinical } \\
\text { follow-up }\end{array}$ \\
\hline$<1 \mathrm{~cm}$ & $22(73.3 \%)$ & 0 & $5(16.6 \%)$ & $2(6.6 \%)$ & $15(50 \%)$ \\
$>1 \mathrm{~cm}$ & $8(26.7 \%)$ & $3(10 \%)$ & 0 & $3(10 \%)$ & $2(6.6 \%)$ \\
Overall & 30 & $3(10 \%)$ & $5(16.6 \%)$ & $5(16.6 \%)$ & $17(56.6 \%)$ \\
\hline
\end{tabular}

Table II. Management of patients attending to angiodysplasia number

\begin{tabular}{lccccc}
\hline Number & $\begin{array}{c}\text { Number } \\
\text { of cases }\end{array}$ & Laparotomy & $\begin{array}{c}\text { Push } \\
\text { enteroscopy }\end{array}$ & $\begin{array}{c}\text { Double balloon } \\
\text { enteroscopy }\end{array}$ & $\begin{array}{c}\text { Clinical } \\
\text { follow-up }\end{array}$ \\
\hline$<10$ & $25(83.3 \%)$ & $3(10 \%)$ & $5(16.6 \%)$ & $3(10 \%)$ & $15(50 \%)$ \\
$>10$ & $5(16.7 \%)$ & 0 & 0 & $2(6.6 \%)$ & $2(6.6 \%)$ \\
Overall & 30 & $3(10 \%)$ & $5(16.6 \%)$ & $5(16.6 \%)$ & $17(56.6 \%)$ \\
\hline
\end{tabular}

We found duodenal angiodysplasia in 10 patients (33.3\%), jejunal angiodysplasia in 25 patients $(83.3 \%)$ and ileal in 15 patients $(50 \%)$. Attending to angiodysplasia location, there were no significant differences in any of the parameters studied.

Considering angiodysplasia size, both groups were comparable in sex and age (Table III). Patients with large $(>10 \mathrm{~mm})$ angiodysplasia had higher transfusion requirements (3 vs. 1.4 units/patient; $\mathrm{p}=0.03$ ), higher possibilities of receiving a therapeutic procedure after CE (75 vs. $18.2 \% ; \mathrm{p}=0.022)$, and a significantly lower hemoglobin concentration (8.12 vs. 9.70; $\mathrm{p}=0.0499)$ as a lower rebleeding rate or persistent anemia $(0 v s .23 \% ; p=0.03)$ (Fig. 1). Two patients died both from a massive GI bleeding detected by CE; both of them had large angiodysplasia. The only medical therapy given to patients who were selected to a clinical follow up was oral iron.

Attending to angiodysplasia number, patients with a higher number of angiodysplasia (> 10) (Table IV) had

Table III. Long term outcome of patients with large size $(>10 \mathrm{~mm})$ and small size $(<10 \mathrm{~mm})$ angiodysplasia on CE

\begin{tabular}{lccc}
\hline & $>10 \mathrm{~cm}$ (8 patients) $<10 \mathrm{~cm}$ (22 patients) & $p$ \\
\hline Age (yr) & $66.6($ SD 12.3) & $68($ SD 11.3) & n.S. \\
Men (\%) & $14(45.4 \%)$ & $16(54.6 \%)$ & n.S. \\
Transfusions previous CE (units/patient) & 3 & 1.4 & 0.03 \\
Hemoglobin pre-CE & 8.12 & 9.70 & 0.0499 \\
Hemoglobin post-CE & 11.72 & 12 & n.S. \\
Number of patients with oral Fe pre-CE & $3(37.5 \%)$ & $17(77.3 \%)$ & n.S. \\
Number of patients with oral Fe post-CE & $3(37.5 \%)$ & $13(59.1 \%)$ & n.S. \\
Therapeutic procedure after CE & $6(75 \%)$ & $4(18.2 \%)$ & 0.022 \\
(number of patients) & & & \\
Mortality & $2(25 \%)$ & $0(0 \%)$ & 0.037 \\
Re-bleeding rate (overt or persistent & $0(0 \%)$ & $5(23 \%)$ & 0.03 \\
anemia) $(\%)$ & & & \\
\hline
\end{tabular}

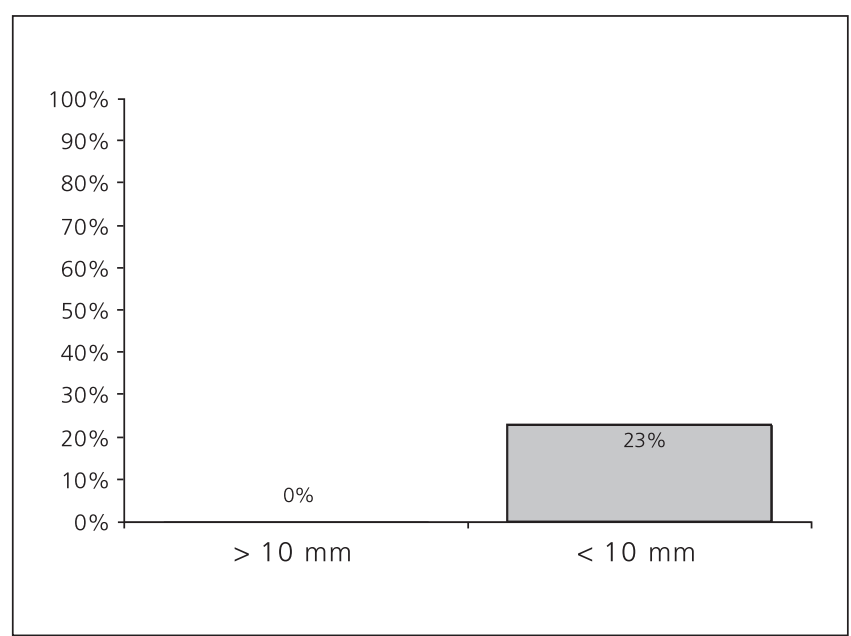

Fig. 1. Rebleeding rates in patients with large $(>10 \mathrm{~mm})$ and small $(<10 \mathrm{~mm})$ angiodysplasia $(p=0.03$; Chi square test).

Table IV. Long term outcome of patients with $>10$ angiodysplasia and $<10$ angiodysplasia on CE

\begin{tabular}{lccc}
\hline & $>10$ (5 patients) & $<10$ (25 patients) & $p$ \\
\hline Age (yr) & $61.3($ SD 11.7) & $68.1($ SD 12) & n.S. \\
Men (\%) & $3(60 \%)$ & $12(48 \%)$ & n.s. \\
Transfusions before CE (units/patient) & 3 & 1.5 & 0.043 \\
Hemoglobin pre-CE (g/dd) & 9.04 & 8 & n.S. \\
Hemoglobin post-CE (g/d) & 7 & 9.04 & 0.036 \\
Number of patients with oral Fe pre-CE & $1(20 \%)$ & $20(80 \%)$ & 0.02 \\
Number of patients with oral Fe post-CE & $0(0 \%)$ & $17(68 \%)$ & 0.053 \\
Therapeutic procedure after CE (number of patients) & $2(40 \%)$ & $10(40 \%)$ & n.S. \\
Mortality & $1(20 \%)$ & $1(4 \%)$ & 0.043 \\
Re-bleeding rate (overt or persistent anemia) $(\%)$ & $2(20 \%)$ & $3(12 \%)$ & n.S. \\
\hline
\end{tabular}

higher transfusion requirements (3 vs. 1.5 units/patient; $\mathrm{p}=0.043)$, lower hemoglobin levels ( $7 v s .9 .04 ; \mathrm{p}=0.036)$ and fewer patients from this group were under oral iron therapy before the CE (20vs. 80\%; $\mathrm{p}=0.02)$. We found no significant differences in the number of neither therapeutic procedures nor rebleeding rate between both groups. One of the patients who died had more than 10 angiodysplasia; the other one had only one large lesion.

Mortality was significantly higher in patients with large angiodysplasia $(25 v s .0 \% ; \mathrm{p}=0.037)$ and with a higher number of small bowel lesions (20vs. 4\%; $\mathrm{p}=0.043)$.

As noted before, 13 patients underwent subsequent interventions after $\mathrm{CE}$, including push enteroscopy in 6 $(16.7 \%)$, laparotomy in $3(10 \%)$ and double balloon enteroscopy in $5(16.7 \%)$. One patient received push enteroscopy and laparotomy. On laparotomy, angiodysplasia were managed with segmental resection in two patients; in the other one angiodysplasia were not found, and anemia resolved spontaneously in the last clinical control. This patient is still under clinical surveillance. Push enteroscopy failed to find angiodysplasia in two patients. The rest who underwent endoscopic procedures (8 patients) were treated with argon gas coagulation with 
subsequent persistent anemia in one. Double-balloon enteroscopy could not be performed in every case previously to surgery because of massive bleeding with hemodinamic instability in some cases. The decision between push enteroscopy and double balloon enteroscopy was made depending on the location of the lesions, reserving push enteroscopy for those placed in the distal duodenum, and double balloon enteroscopy for the rest, with an upper, lower or both accesses.

Seventeen patients did not undergo further procedures despite a positive $\mathrm{CE}$. The main reasons for not having any further intervention were patient's or physician's concerns about enteroscopy (53\%), and the absence of clinical or analytical signs of rebleeding (47\%).

On follow up rebleeding was detected in 5 patients (16.7\%), all of them with angiodysplasia of less than $10 \mathrm{~mm}$ diameter, with no statistical differences considering the number of small-bowel angiodysplasia. Patients who did not have further interventions were comparable to patients who received a therapeutic procedure, except for rebleeding rate (occult or overt) which was significantly more frequent in the former group $(23.53 \mathrm{vs} .7 .69 \%$; $\mathrm{p}=$ 0.037) (Fig. 2). Mean hemoglobin level improved globally (8.6vs. 11.7; $\mathrm{p}=0.005)$, with complete anemia resolution in 13 patients $(43 \%)$, and with a subjective clinical improvement in 24 patients $(80 \%)$, despite anemia was not completely resolved in all of them. As noted previously, rebleeding was not found in patients with large $(>10 \mathrm{~mm})$ angiodysplasia.

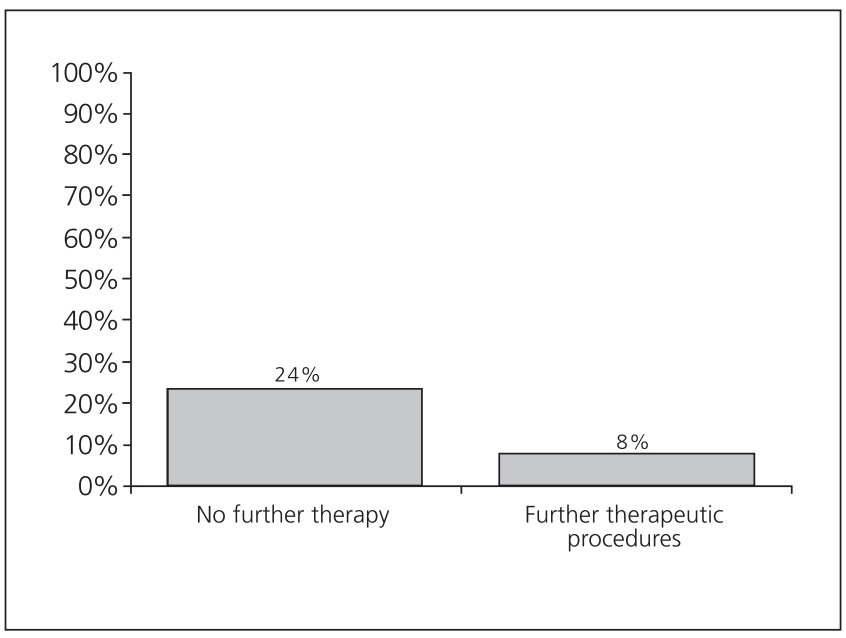

Fig. 2. Rebleeding rates in patients with only clinical follow-up and patients which received a further therapeutic procedure $(p=0.037$; Chi square test).

\section{DISCUSSION}

CE is a relatively novel technology with a poor definition of its impact on patients' outcome. Small and previously non observable lesions can be now discovered, but the clinical relevance of those findings is still undeter- mined. Former studies have been focused on long term rebleeding rate in patients with OGIB as the main end point (5-8), and some have determined the long term clinical outcome of these patients, whether they had positive findings or not (9). Nevertheless, to our knowledge no study specifically focused on patients with angiodysplasia has been reported.

Angiodysplasia is a usual source of obscure gastrointestinal bleeding, the most prevalent in most studies focused in CE's diagnostic yield for OGIB $(5,6,12,13)$. However, no differences have been established in order to define which of those lesions are of clinical relevance, or need a specific therapy, because sometimes angiodysplasia are observed as irrelevant findings in patients with neither anemia nor overt bleeding (14).

In our study, rebleeding rate is lower than previously described (9-11) a $16.6 \%$ of our patients. In previous works, reported rebleeding rates as high as $58.3 \%$ made of angiodysplasia one of the lesions with a higher rebleeding risk. In contrast, ours has shown a much lower rebleeding rate, possibly related to the therapeutic procedures performed in cases with a greater clinical impact (lower hemoglobin levels, higher transfusion requirements). Interestingly, a substantial proportion $(67 \%)$ of patients with angiodysplasia did not undergo further interventions in our study, which allowed us to observe the natural history of those lesions.

Paradoxically, patients with large angiodysplasia, which had a higher clinical impact (denoted by higher transfusion requirements, lower hemoglobin levels and a noteworthy mortality rate) (2 patients; $25 \%$ ) (Table III) had no rebleeding episodes. This may be explained by the higher proportion of patients from this group who received therapeutic procedures, and by the mortality, which could have been selected the patients with a greater rebleeding risk. Indeed, therapeutic procedures were more frequently performed in this group because bigger lesions are usually better localized in enteroscopy and they had a higher clinical impact, inducing the gastroenterologist to ask for a therapeutic procedure.

On the other hand, patients with small angiodysplasia (Fig. 3), which had a lower percentage of therapeutic procedures carried out (18\%), maybe because they are usually quite difficult to observe by endoscopy and subjectively considered of a lesser relevance by gastroenterologists, accounted the entire rebleeding rate. This can be explained by the difficulty of treating small angiodysplasia, especially when they are multiple and disperse in the small bowel. Nevertheless morality was absent in this group.

These results might have been different if other medical therapy but oral iron would have been given. Some case reports have described the positive influence of octeotride or hormonal therapy (15), but our patients did not receive any of those therapies.

These findings support that patients with large angiodysplasia would benefit from further therapeutic interventions. The lower clinical impact of small angiodyspla- 


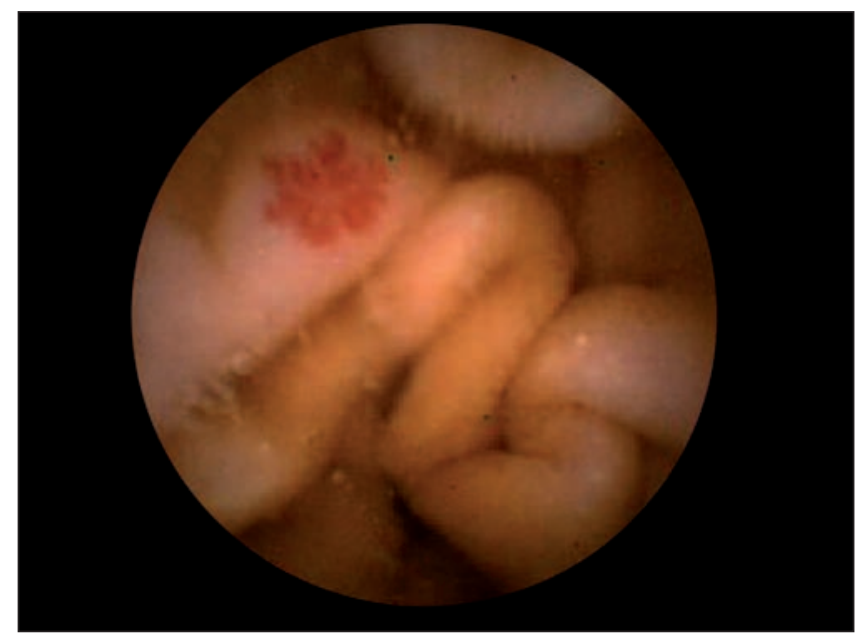

Fig. 3. Small angiodysplasia (< $10 \mathrm{~mm})$.

sia indicates that it seems reasonable to reconsider patients with rebleeding or persistent anemia in due course and provide therapy, in a secure fashion. After one year, according to previous reports (9), rebleeding is odd, and further procedures should be scarcely required.

When considering angiodysplasia number, patients with more than 10 angiodysplasia had also a greater clinical impact (higher transfusion requirements, lower hemoglobin levels). Nevertheless, there were no differences between both groups neither in the number therapeutic procedures performed nor rebleeding rates. Mortality was significantly higher in the $>10$ angiodysplasia group. This difference has to be confirmed in further studies as one patient dead in each group, and more patients should be included to validate our finding.

Therapeutic procedures were attempted in 13 patients. The global rate of a specific and successful therapy derived from those procedures was $76.92 \%$ (10 patients) as angiodysplasia were not found in three patients. Interestingly, there was not mortality among these patients, and most of them had no sign of rebleeding after one year. Thus, patients who received therapeutic measures seldom re-bled on follow-up (7.67\%).

On follow up, only patients with small angiodysplasia re-bled. An explanation to this fact may be that clinicians should rest importance to those small lesions, because it is known that a relatively important proportion of healthy asymptomatic subjects may have small bowel irrelevant lesions on CE (14). Notably, an important proportion of patients improved without a specific measure. Some, indeed, recovered hemoglobin levels to normality. This suggests that angiodysplasia could re-bleed in an intermittent fashion, with a spontaneous stop in many cases. Then, in selected cases, with small isolated lesions, clinical follow-up with or without additional medial therapies might be the best choice.

Some potential drawbacks of our work are the short sample size, which warrants more studies with a higher

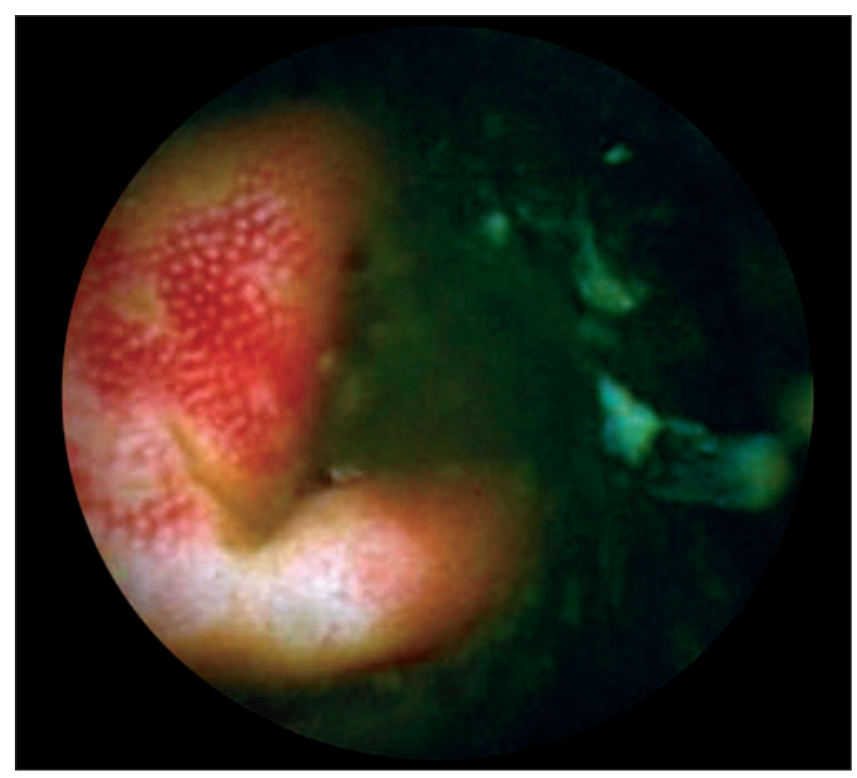

Fig. 4. lleocecal valve. Large angiodysplasia (> $10 \mathrm{~mm}$ ).

number of patients included, and the relatively inexact, though widely reported in other papers, size estimation. In fact, other authors have manage this limitation the same way as us, in fields in which size is much more relevant, as polyps size estimation (16).

Duodenal angiodysplasia were not found in upper endoscopy. Most of them were located in the third or fourth portion and were relatively small, which could explain why they were overlooked. Nevertheless, a second endoscopy study is advisable in patients with OGIB with a suboptimal first endoscopic workup.

In conclusion, our work shows that patients with large size $(>10 \mathrm{~mm})$ small bowel angiodysplasia have a higher clinical impact and a better chance to receive a therapeutic invasive intervention. Instead, angiodysplasia number did not determine neither re-bleeding rates nor therapeutic possibilities. Our series show a lower rebleeding rate than previous works for those patients (9). Re-bleeding in patients without an aggressive intervention during follow up is not scarce, and a medical therapy other than oral iron should be studied for those patients.

\section{REFERENCES}

1. Ell C, Remke S, May A, Helou L, Henrich R, Mayer G. The first prospective controlled trial comparing wireless capsule endoscopy with push enteroscopy in chronic gastrointestinal bleeding. Endoscopy 2002; 34: 685-9.

2. Costamagna G, Shah SK, Riccioni ME, Foschia F, Mutignani M, Perri $\mathrm{V}$, et al. A prospective trial comparing small bowel radiographs and video capsule endoscopy for suspected small bowel disease. Gastroenterology 2002; 123: 999-1005.

3. Voderholzer WA, Ortner M, Rogalla P, Beinhölzl J, Lochs H. Diagnostic yield of wireless capsule enteroscopy in comparison with computed tomography enteroclisis. Endoscopy 2003; 35: 1009-14. 
4. Neu B, Ell C, May A, Schmid E, Riemann JF, Hagenmüller F, et al Capsule endoscopy versus standard test in influencing management of obscure digestive bleeding: Result from a German multicenter trial. Am J Gastroenterol 2005; 100: 1736-42.

5. Rastogi A, Schoen RE, Slivka A. Diagnostic yield and clinical outcomes of capsule endoscopy. Gastrointest Endosc 2004; 60: 959-64.

6. Pennazio M, Santucci R, Rondonotti E, Abbiati C, Beccari G, Rossini FP, et al. Outcome of patients with obscure gastrointestinal bleeding after capsule endoscopy: Report of 100 consecutive cases. Gastroenterology 2004; 126: 643-53.

7. Delvaux M, Fassler I, Gay G. Clinical usefulness of the endoscopic video capsule as the initial intestinal investigation in patients with obscure digestive bleeding: Validation of a diagnostic strategy based on the patient outcome after 12 months. Endoscopy 2004; 36: 1067-73.

8. Saurin JC, Delvaux M, Vahedi K, Gaudin JL, Villarejo J, Florent C, et al. Clinical impact of capsule endoscopy compared to push enteroscopy: 1-year follow up study. Endoscopy 2005; 37: 318-23.

9. Lai LH, Wong GL, Chow DK, Lau JY, Sung JJ, Leung WK, et al Long term follow-up of patients with obscure gastrointestinal bleeding after negative capsule endoscopy. Am J Gastorenterol 2006; 101: 1224-8.
10. Enns R, Go K, Chang H, Pluta K. Capsule endoscopy: A single-center experience with the first 226 capsules. Can J Gastroenterol 2004; 18 : 555-8.

11. Maieron A, Hubner D, Blaha B, Deutsch C, Schickmair T, Ziachehabi A, et al. Multicenter retrospective evaluation of capsule endoscopy in clinical routine. Endoscopy 2004; 36: 864-8.

12. Kovacs TO. Small bowel bleeding. Curr Treat Options Gastroenterol 2005; 8: 31-8.

13. Mata A, Bordas JM, Feu F, Ginés A, Pellisé M, Fernández-Esparrach $\mathrm{G}$, et al. Wireless capsule endoscopy in patients with obscure gastrointestinal bleeding: A comparative study with push enteroscopy. Aliment Pharmacol Ther 2004; 20: 189-94.

14. Goldstein JL, Eisen GM, Lewis B, Gralnek IM, Zlotnick S, Fort JG. Video capsule endoscopy to prospectively assess small bowel injury with celecoxib, naproxen plus omeprazole and placebo. Clin Gastroenterol Hepatol 2005; 3: 133-41.

15. Hodgson H. Hormonal therapy for gastrointestinal angiodysplasia. Lancet 2002; 359 (11): 1630-1.

16. Burke CA, Santisi J, Church J, Levinthal G. The utility of capsule endoscopy small bowel surveillance in patients with polyposis. Am J Gastroenterol 2005; 100: 1498-502. 